\title{
Eficient Budget Oriented Scheme in Construction Technology and Management
}

\author{
Rakesh gupta* (M. Tech), Ramesh kumar batra* (HOD), Subhash kumar* \\ (Assistant prof.) \\ Department of Civil engineering \\ Institute of Professional Studies Gwalior
}

\begin{abstract}
The role the construction industry plays in socio-economic development is significant. It provides the basis upon which other sectors can grow by constructing the physical facilities required for the production and distribution of goods and services. The construction industry has a significant multiplier effect on the economy as a whole. Cost is one of the primary measures of a project's success. This is true, especially for public projects in developing countries like India, because public construction projects in these countries are executed with scarce financial resources. In this paper we proposed an efficient budget oriented optimized cost overgrow scheme in Construction Technology and Management (CTM) system. Our proposed scheme solved the cost overgrow problem and improved the overall effect of the construction industry projects. The experimental results of our proposed scheme showed the effectiveness compared with existing works.
\end{abstract}

Keywords: CTM, Cost Overgrow, Construction Industry

\section{Introduction}

The role the construction industry plays in socio-economic development is significant. It provides the basis upon which other sectors can grow by constructing the physical facilities required for the production and distribution of goods and services. The construction industry has a significant multiplier effect on the economy as a whole.

The interrelationship between the construction industry and the broader economy largely emanates from three of the industry's characteristics namely: as follows:

$\rightarrow$ The public sector is its major client;

$\rightarrow$ It's large size, ability to produce investment or capital goods which contribute significantly to national GDP; and

$\rightarrow$ It is a major source of employment, directly and indirectly by its multiplier effect.

\section{Problem Statement}

Completion alone does not constitute success for the project owner. For the owner, much of the success of a project depends on many factors, the most important of which is project completion within specified cost parameters (i.e. within a specified budget). The second most important factor affecting success is on time completion as delays in completion of facilities often directly equate to financial losses due to lack of revenue from facility operation.

In India, the present state of the construction industry falls short of meeting domestic and international quality standards and the performance demand expected from the sector. Construction projects have problems with construction techniques and management as well as limitation of funds and time. The critical problems are inability to complete the projects on schedule, low quality work and cost overgrow. In general, most construction projects experience time overgrow and cost overgrows during their execution phase. An examination of the records of more than four thousand construction projects showed that projects were rarely finished on time or within the allocated budget. Previous researchers have also observed that time and cost overgrows are common in the construction industry worldwide.

\section{Objectives of My Thesis Work}

This thesis will be undertaken with the following main objectives.

1. Identifying the main causes of cost overgrow and their overall effects for public building construction projects.

2. Identifying the related responsible party to the causes of cost overgrow.

3. identifying the rate of cost overgrow for various types of public building construction Projects.

4. Identifying the relationship between rate of cost overgrow and contract amount. 
5. Forwarding recommendations to minimize or to avoid cost overgrow and frequency of its occurrence; and hence to reduce its consequential effects on public building construction projects.

\section{Literature Survey}

\section{Construction Project}

Construction project is a mission, undertaken to create a unique facility, product or service

within the specified scope, quality, time, and cost . In practice, however, some construction projects encounter cost overrun, delay on completion time or poor workmanship upon completion. Cost overrun, poor quality workmanship and delay of construction projects require an in-depth investigation to improve the outputs of the construction industry.

It is not uncommon to see construction projects failing to achieve their mission of creating facilities within the specified cost and time. Hardly few projects get completed on time and within budget since construction projects are exposed to uncertain environments because of such factors as construction complexity; presence of various interest groups such as the project owners, end users, consultants, contractors, financiers; materials, equipment, project funding; climatic environment; the economic and political environment and statutory regulations. The successful execution of construction projects, keeping them within estimated cost and the prescribed schedules, primarily depends on the existence of an efficient construction sector capable of sustained growth and development in order to cope with the requirements of social and economic development and to utilize the latest technology in planning and execution.

Cost overrun is common in infrastructure and building construction projects. Researches on construction projects in some developing countries indicate that by the time a project is completed, the actual cost exceeds the original contract price.

\section{Definition of Cost Overrun}

a) Costs overrun:: An instance in which the provision of contracted goods or services are claimed to require more financial resources than was originally agreed between a project sponsor and a contractor.

b) Cost overrun: The amount by which actual costs exceed the baseline or approved costs.

c) Cost overrun:: The difference between the original cost and the actual cost when the project is completed used the word cost growth instead of cost overrun.

For the purpose of this research cost overrun is defined as the difference between the final actual cost of a construction project at completion and the contract amount, agreed by and between the client (the project owner) and the contractor during signing of the contract.

\section{Construction Cost Underestimation}

A more serious situation can confront an owner when there has been deliberate underestimating of costs in order to obtain project approval or for fraudulent practices.

According to studies made in large projects have been intentionally underestimated in order to obtain voter support for the financing approvals. He stated that whatever the cause, almost al large public projects contain initial cost estimating errors that result in the need for increased funding to complete the projects.

Construction cost increases seem to materialize after the commencement of the construction but the problem is deep-rooted during contract cost estimation and tendering stage.

Generally cost underestimation come in four types:

- Technical

- Economic

_ Psychological, and

Political

\section{a) Technical Explanations}

Most studies that compare actual cost at completion and estimated costs at the beginning of bid award of construction projects explain what they cal "forecasting errors" in technical terms, such as imperfect techniques, inadequate data, honest mistakes, inherent problems in predicting the future, lack of experience on the part of forecasters, etc..

\section{b) Economical Explanations}

Economic explanations consider cost underestimation in terms of economic rationality.

Two types of economic explanations exist; the first explained in terms of economic self-interest, the other in terms of the public interest. As regards self-interest, when a project goes forward, it creates work for engineers and construction firms, and many stakeholders make money. If stakeholders are involved in or indirectly influence the forecasting process, then this may influence the outcomes.

As regards the public interest, project promoters and forecasters may deliberately underestimate costs in order to provide public officials with an incentive to cut costs and thereby to save the public's money. Empirical studies have identified promoters and forecasters who say they underestimate costs in order to save public money. The 
argument has also been adopted by scholars, for instance explicitly concludes that "keeping costs low is more important than estimating costs correctly".

Both types of economic explanation account well for the systematic underestimation of costs. Both depict such underestimation as deliberate, and as economically rational.

\section{c) Psychological Explanations}

Psychological explanations attempt to explain biases in forecasts by a bias in the mental makeup of project promoters and forecasters. Politicians may want a monument complex or museums, and transportation officials sometimes have the mentality of building roads and bridges. The most common psychological explanation is probably "appraisal optimism." According to this explanation, promoters and forecasters are held to be overly optimistic about project outcomes in the appraisal phase, when projects are planned and decided. An optimistic cost estimate is a low one. The existence of appraisal optimism in promoters and forecasters would result in actual construction costs being higher than estimated costs.

\section{d) Political Explanations}

Political explanations interpret cost underestimation in terms of interests and power A key question for political explanations is whether forecasts are intentionally biased to serve the interests of project promoters in getting projects started. For legal, economic, moral, and other reasons, if promoters and forecasters have intentionally fabricated a deceptive cost estimate for a project to get it started, they are unlikely to tell researchers.

Incentives versus transaction costs: a theory of procurement contracts Patrick Bajari and Steven Tadelis showed that cost-plus contracts are preferred to fixed-price contracts when a project is more complex. They briefly discuss how fixed-price or cost-plus contracts might be preferred to other incentive contracts. Finally, our model provides some micro foundations for ideas from Transaction Cost Economics. Inspired by facts from the private-sector construction industry, they develop the model that explains many stylized facts of procurement contracts.

The implications of their analysis are relevant to both the private and public sector as to how procurement should be conducted. As the Federal Acquisition Rules (FARs) prescribe, government procurement is guided almost solely by fixed-price contracts. A common justification is that competitive bidding reduces the risk of ad hoc selection and corruption.

But for complex systems, particularly in defense and aerospace, this approach may have high costs [1].

\section{THE DEVELOPMENT OF ASUSTAINABLE-CONSTRUCTION PLANNING SYSTEM}

Javier Irizarry and Samaneh Zolfagharian and Mehdi Nourbakhsh developed a prototype of a SustainableConstruction Planning System (SCPS) in order to mitigate the negative impacts of the construction industry on the environment. To achieve this aim, frequency and severity of known environmental impacts of construction process of residential buildings were investigated through interviews with a safety expert panel in Malaysia. Then, risk level associated with each environmental impact was calculated based on the relevant risk matrix. The SCPS extracts current construction activities from any computer-based schedule (Microsoft Project ${ }^{\circledR}$ in this study) and identifies sustainable strategies, and environmental impacts related to each activity as a report. The SCPS was presented to an expert panel who was asked to assess the reliability and usability of the SCPS. It can be concluded that the SCPS is efficient and helpful in mitigating construction related impacts on the environment. The practical implication of this study is to promote sustainable construction by promoting the project participants' knowledge and awareness of significant environmental impacts related to construction operations.

This study is to develop and test a prototype to integrate construction schedules with sustainable construction indicator databases: Environmental Impacts databases, Construction Activities databases, risk assessment databases, and Sustainable Strategies databases. Although the SCPS can be integrated to any construction schedule, the developed databases are limited to residential construction projects.

Future research needs to investigate environmental impacts and sustainable strategies related to different construction projects such as high-rise buildings and commercial buildings. In addition, these databases cover five common construction activities such as earth working, reinforcing, concreting, form working, and masonry [2].

Sustainability of concrete construction in Indian context B. Bhattacharjee believes that large-scale mechanisation for production of engineered concrete with mineral and chemical admixtures, with right quality control scheme, can lead to better sustainability of concrete in India. The discussions presented above leads to the conclusion that there is a need for being concerned about sustainability of concrete in India and minimising 
the $\mathrm{CO} 2$ emission. There is also a need to minimise wastage of precious natural resources by making their efficient and judicious use. This is possible by large-scale mechanisation of concrete construction in the country through extensive use of batching plant, RMC practices and prefabrication wherever possible. Further use of six components namely, coarse aggregate, fine aggregate, water, OPC cement with mineral admixture/blended cement and plasticiser for production of engineered concrete, instead of non-engineered/semi-engineered concrete production with four components, can make concrete sustainable in India [3 ].

\section{Proposed Methodology}

The research is a practical problem developed from the observation of construction projects and the research questions are oriented to investigate the cause of cost overgrow and their effects. This research can be categorized as applied, exploratory, descriptive and co-relational type. It is applied and exploratory because the research was initiated from practical problems and finds whether there exists cost overgrow or not. It is also descriptive and co-relational because it tried to describe the actual rate of cost overgrow and the variables of cost overgrow and tries to draw relationship between contract amount and rate of cost overgrow in the Ethiopian public building construction projects.

\section{The study scope and limitation}

Cost overgrow in building construction projects are caused by many factors. Each causes of cost overgrow have different rates of occurrences and their impact on the final cost of the construction project also varies. Therefore, it is important to identify both key causes of cost overgrow based on their occurrence and their impact on building construction projects. The effects of cost overgrow on the stakeholders, on the construction industry, and on the national economy of the country will be identified.

The research work was not without its problems and limitations which were encountered throughout the preparation of this research. Its limitation is the unavailability of adequate documented information in the field of the study, and the reluctance of some stakeholders in the construction industry to provide information related to cost.

\section{Data Source and Collection}

The study has used the data sources to produce the following basic documents: respondents' documents and archival documents. The respondents' documents were collected using questionnaires from clients (project owners), contractors and consultants. There are two basic types of survey questions from which to choose: open-ended and closed-ended. This questionnaire survey has both open-ended and closed-ended questionnaires. Archival documents were mostly from completed projects, in which contract documents, project reports, correspondence letters and payment certificates were investigated thoroughly which were very important in identifying the recurrent problems related to cost in the Indian building construction sector. In addition, they helped to judge how problems on causes of cost overgrow arise and how they are documented Data collection part of the research is the most tiresome part; the most difficult one is the respondents' reluctance to react as per their promised schedule. The time schedule that was allocated to the research and respondents reluctance not to respond quickly made the research stressful for the period of data collection.

Owing to the large number of public agencies that own construction projects and the large number of contracting and consulting companies that undertake work for public agencies a survey by questionnaire was found appropriate in addition to the desk study. The questionnaire was carefully designed in light of getting high response rate from respondents.

The answers for the structured part of the questionnaire are based on Likert's-scale of five ordinal measures of agreement towards each statement (from 0 to 4 ) as shown in the following sections. The reasons for adopting this simple scale are:

$\rightarrow$ To provide simplicity for the respondent to answer, and

$\rightarrow$ To make evaluation of collected data easier

Likert's-scale is important to know respondents' feelings or attitudes about something. The respondents must indicate how closely their feelings match with the question or statement on a rating scale.

After the variables of cost overgrow in building construction projects are identified; respondents are asked about their agreement on these variables in causing cost overgrow. Accordingly the respondents choose one of the following based on their feeling.

$\rightarrow$ I strongly disagree

$\rightarrow$ I don't agree

$\rightarrow$ Neutral

$\rightarrow$ I agree

$\rightarrow$ I strongly agree 
After expressing their agreement and/or disagreement on the variables of cost overgrow respondents are asked about the chances of occurrences of these variables based on the following choices.

0 - Not at al $=0 \%$ probability to happen

1- Unlikely $=0 \%-25 \%$

2- Likely $=26 \%-50 \%$

3- Almost certain $=51 \%-99 \%$

4- Certain $=100 \%$ probability to happen

After identifying the chances of occurrence of the cost overgrow variables respondents were asked about the impacts of each causes of cost overgrow based on the following choices.

0 - No significance

1- Minor significance

2- Average significance

3- High significance

4- Extreme significance

After data is gathered on causes of cost overgrow, the responsible party from stakeholders in the construction industry has to be identified for the cause of cost overgrow; the questionnaires are prepared in such a way that detailed information can be gathered in a systematically prepared matrix table.

The research samples are taken from stakeholders in the construction industry which are clients (project owners), contractors and consultants, that are selected depending on their direct exposure to building construction activities.

\section{Method of Analysis}

Both descriptive and inferential statistics are employed in the data analysis. In the analysis the "Mean Score" method is adopted to establish the relative importance of the causes of cost overgrow for public building construction projects in India. As discussed earlier Likert's scale of five ordinal measures of agreement towards each statement is used to calculate the mean score for each factor that is used to determine the relative ranking. The mean score (MS) for each variables of cost overgrow is computed by using the following formula;

$$
M S=\frac{\sum(f x S)}{\mathrm{N}}
$$

Where:

MS - Mean Score

$\mathbf{f}-$ Frequency of responses for each score

$\mathbf{S}$ - Scores given to each factor (from 0 to 4 )

$\mathbf{N}$ - Total number of responses concerning each factor

The Spearman (rho) rank correlation coefficient is used for measuring the differences in ranking between two groups of respondents scoring for various factors (i.e. clients versus consultants, clients versus contractors, and consultants versus contractors). The Spearman (rho) rank correlation coefficient for any two groups of ranking is given by the following formula:

\section{Spearman rank correlation coefficient $=\left[1-\left\{6 x \sum\right.\right.$ (The difference in ranking between} each pair of factors $\left.\left.)^{2}\right\} / N X\left(N^{2}-1\right)\right]$

\section{Procedure for hypothesis testing:}

1. Define the null hypothesis $(\mathrm{H} 0)$ and the alternative hypothesis (HA)

2. Choose a value for the significance level

3. Calculate the value of the test statistic, Spearman rank correlation coefficient.

4. Compare the calculated value with a table of the critical values of the test statistic.

5. If the calculated value of the test statistic is less than the critical value from the table, accept the null hypothesis (H0). If the absolute (calculated) value of the test statistic is greater than or equal to the critical value from the table, reject the null hypothesis (H0) and accept the alternative hypothesis (HA).

\section{Results Analysis}

This part of the research deals with the analysis and discussion of the data gathered from the desk study and questionnaire survey. It includes the identification of the existence and extent of cost overgrow, relationship between rate of cost overgrow and contract amount, main causes of cost overgrow, rate of occurrences of variables of cost overgrow, the impact of the variables of cost overgrow on the final/total cost of the project. Finally, the effects of cost overgrow on the various stakeholders, on the construction industry, and on the national economy in general will be dealt.

The procedure used in analyzing the results was aimed at establishing the relative importance of the various factors responsible for cost overgrow and their effects. The questionnaire gave each respondent an opportunity 
to identify the factor that was likely to cause cost overgrow by giving the response "I strongly disagree", "I disagree", "I agree", etc...; frequency occurrence of the variables of cost overgrow ; and the impacts of each cost. Overgrow variables on the final cost of the project. For each variables of cost overgrow, the percentages of respondents' response were ranked for analysis purpose. On the basis of the ranking of the variables by the various groups, it was possible to identify the most important factors that influenced cost overgrows in public building construction projects. From the desk study a variety of completed public building construction projects throughout Ethiopia were surveyed. During the desk study al the documents of each project such as correspondence letters, project report, payment certificate, the contract amount, contract time during signing of the contract actual cost and actual completion time at completion of the project were thoroughly investigated. These help to understand the reasons behind each project for cost overgrow, and to investigate how the actual cost at completion deviates from the contract amount. Collecting these data helped to analyze and draw the relationship between rate of cost overgrow and contract amount.

\section{Hypothesized Causes of Cost overgrow}

1. Inflation or increase in the cost of construction materials

2. Lack of planning and coordination or less emphasis to planning

3. Fluctuations in the cost of labor and/or material or any other mater affecting the cost of the execution of the works and subsequent legislation that affect the project

4. Insufficient geotechnical investigation

5. Additional costs due to variations works

6. Change in foreign exchange rate (for imported materials)

7. Change orders and/or lack of control on excessive change orders

8. Costs due to special risks which very often include outbreak of war, projectile missile, hostilities, contamination and other such risks

9. Delay of drawings and/or order requested by the contractor in accordance with Sub Clause

10. Changes in Plans and drawings

11. Inappropriate/inexperienced contractor

12. Encountering of not foreseeable physical obstructions and conditions

13. Failure to identify problems and institute necessary and timely design and programming changes

14. Failure on the part of the employer to give possession of the site in accordance with the terms of the contract

15. Inaccurate quantity estimate or excess quantity during construction

16. Unclear specifications or changes to specification

17. Contractors bankruptcy

18. Cost under estimation

19. Additions and/or enhancement required by clients or end users

20. Difficulties in obtaining construction materials in the local market

21. Errors in setting out which are based on incorrect written data supplied by the Engineer

22. Ambiguities or discrepancies of documents

23. Loss or damage due to excepted risks or employers risk

24. Suspension of work ordered by the Engineer

25. Complexity of construction projects

26. Poor communication among contractor, consultant, and the client

27. Mistakes during construction or defective

28. Supplementary/additional agreement

29. Cost associated with test of samples not provided in the contract

30. Funding problems or client's shortage of finance or delayed payments to contractors

31. Lack of end user involvement

32. Executive bureaucracy in the client's organization

33. Uncovering of works that has already been completed, but they are found to be executed in accordance with the contract

34. Acceleration required by the owner (shortening of contract time)

35. Indemnities that the employer has contractually undertaken to assume

36. Different consultant for Design, Supervision \& Contract Administration

37. Increase in tax/change in government fiscal/monetary policies

38. Searching for defects which are not the fault of the contractor

The major causes of cost overgrow are inflation or increase in the cost of construction materials, poor planning and coordination or less emphasis to planning, fluctuation in the cost of materials according. 
Domestic contractors tolerate delayed hand over of construction sites but foreign contractors do not tolerate delayed hand over of construction sites by employers; foreign contractors claim to be compensated for idle hours of man power and equipments due to the delay. These are due to cultural differences between domestic contractors and foreign contractors; domestic contractors which suffered from delayed payments and late site hand over, say that such tolerance is to avoid adversarial relationship with the stakeholders on that project and hence to create conducive working environment. Actually, this is not the only reason for such tolerance; sometimes they tolerate such things to escape penalties due to their own mistakes, one of the commonest contractors' problems is delay due to their own problems. Contrary to the literature review, increase in work men's wage cannot be causes of cost overgrow in the case. If there is an increase in work men's wage due to inflation or due to some other problems in the country, this increased wage rate will be shouldered by the contractor, it will not pass to the project owner as in the case of rise in the cost of cement, fuel, reinforcement bar and asphalt. In the Ethiopian construction industry the contractor can be compensated for the increase in the cost of cement, fuel, reinforcement bar and asphalt. For other items, unless and otherwise specified in the particular conditions of contract, price increase is not compensable for contractors.

\section{Identifying Causes of Cost Overgrow based on Rate of Occurrence}

The most frequent causes of cost overgrow were assessed from respondents and results are given. The causes of cost overgrow which have a mean score of greater than or equal to $2(\mathrm{MS}>=2$ ) rate of occurrence are considered as important because there is at least a probability of $50 \%$ chance for the occurrence.

\section{Hypothesized Causes of Cost Overgrow}

1. Inflation or increase in the cost of construction materials

2. Fluctuations in the cost of labor and/or material or any other mater affecting the cost of the execution of the works and subsequent legislation that affect the project

3. Change in foreign exchange rate (for imported materials)

4. Change orders and/or Lack of control on excessive change orders

5. Lack of planning and coordination or less emphasis to planning

6. Additional costs due to variations works

7. Failure to identify problems and institute necessary and timely design and programming changes

8. Changes in Plans and drawings

9. Insufficient geotechnical investigation

10. Contractors bankruptcy

11. Difficulties in obtaining construction materials in the local market

12. Cost under estimation

13. Inaccurate quantity estimate or excess quantity during construction

14. Delay of drawings and/or order requested by the contractor in accordance with Sub Clause

15. Inappropriate/Inexperienced contractor

16. Unclear specifications or changes in specification

17. Supplementary/additional agreement

18. Ambiguities or discrepancies of documents (Clause

19. Poor communication among contractor, consultant, and the client

20. Encountering of not foreseeable physical obstructions and conditions

21. Executive bureaucracy in the client's organization

22. Suspension of work ordered by the Engineer

23. Failure on the part of the employer to give possession of the site in accordance with the terms of the contract

As indicated on above, inflation or increase in the cost of construction materials, change in foreign exchange rate, and lack of planning and coordination or less emphasis to planning, change orders or variation orders are the top most frequently encountered causes of cost overgrow. Whereas force majeure related causes of cost overgrow such as outbreak of war, hostilities, uprisings, etc., are rarely encountered in the Ethiopian construction industry. Since the occurrences of causes of cost overgrow related to force majeure are rare, they have low rank.

\section{Identifying of causes of cost overgrow based on Impact}

As discussed previously identifying the rate of occurrence only wil not help in identifying factors that are critical in causing cost overgrow; regardless of the chance of occurrence the significance of the factor independently has to be gauged with respect to its severity, when it happens during construction phase.

\section{Hypothesized Causes of Cost Overgrow}


1. Inflation or increase in the cost of construction materials

2. Fluctuations in the cost of labor and/or material or any other mater affecting the cost of the execution of the works and subsequent legislation that affect the project

3. Costs due to special risks which very often include outbreak of war, projectile missile, hostilities, contamination and other such risks

4. Change in foreign exchange rate (for imported materials)

5. Additional costs due to variations works

6. Changes orders or lack of control on excessive change orders

7. Insufficient geotechnical investigation

8. Difficulties in obtaining construction materials in the local market

9. Ambiguities or discrepancies of documents

10. Encountering of not foreseeable physical obstructions and conditions

11. Contractors bankruptcy

12. Inappropriate/Inexperienced contractor

13. Lack of planning and coordination or less emphasis to planning

14. Failure to identify problems and institute necessary and timely design and programming changes

15. Changes in Plans and drawings

16. Failure on the part of the employer to give possession of the site in accordance with the terms of the contract

17. Inaccurate quantity estimate or excess quantity during construction

18. Cost under estimation

19. Unclear specifications or changes in specification

20. Additions and/or enhancement required by clients or end users

21. Funding problems or client's shortage of finance or delayed payments to contractors

22. Mistakes during construction or defective work

23. Supplementary/additional agreement

24. Loss or damage due to excepted risks or employers risk

25. Complexity of construction projects

26. Executive bureaucracy in the client's organization

27. Indemnities that the employer has contractually undertaken to assume

28. Poor communication among contractor, consultant, and the client

The above finance related causes of cost overgrow such as inflation or increase in the cost of construction materials, fluctuation in the cost of materials according to conditions of contract, etc and force majeure related such as outbreak of war, up risings, etc have higher impact on the final cost of the project at completion. Even if force majeure related causes of cost overgrow have severe impact on the final cost of the project at completion their rate of occurrence is low.

\section{Effects of Cost Overgrow}

Although the degree of effects of cost overgrow varies on the stakeholders in the construction industry, al the parties involved are affected by cost overgrow. The first victim of cost overgrow would be the project owner since he has envisaged his construction project to be realized within an allocated cost and time frame. Anything outside these stated frames are cost overgrow and time overgrow to the client. Cost overgrow does not affect only those parties that are involved directly in the construction of a project, but its effects pass to the construction industry as a whole and consequently to the national economy of the country. Cost overgrow for public clients, whose financial resources are scarce, has many effects and it will be a source of friction between the public client and the consultant. When the cost overgrows is due to financial constraints of clients, the construction projects suffer lots of problems which further aggravate the problems of cost overgrow. For public projects cost overgrow will lead to delay as the public clients do not have enough financial resources which are ready to be pumped to the construction project, they require new approval for these additional costs from higher public officials or Ministry of Finance and Economic Development, in doing so time will go on and consequent delay on the project will crop up. Which lead to further cost overgrow as a construction project is delayed for a long period of time it will be subjected to inflationary pressure and interests will be accumulated.

Even if it is not common in the Ethiopian construction industry to abandon a public building construction project due to cost overgrow, projects suffer excessive delay from cost overgrow, which subsequently lead to additional cost overgrow as the duration of a project is extended the price of materials will rise which subsequently lead to additional costs not only to the project owner but also to the contractor and to the consultant which participate on that project until completion. And the contractor will incur an additional cost due to idle man power and idle equipments. Generally, the following are the main effects of cost overgrow which are collected from the respondents of the questionnaire survey and desk study. 
1. Delay,

2. Supplementary agreement,

3. Additional cost, budget short fall,

4. Adversarial relationship between participants of the project,

5. Loss of reputation to the consultant, the consultant will be viewed as incompetent by project owners,

6. High cost of supervision and contract administration for consultants,

7. Delayed payments to contractors,

8. The contractor will suffer from budget short fall of the client,

9. Poor quality workmanship,

10. Dissatisfaction by project owners and consequently by end users,

11. Negative attitude towards the construction industry by the higher public authority and by the society as a whole,

12. The contribution of the construction industry to the growth of national economy of the country will be less,

13. Cost overgrows in construction projects prevent the planned increase in property and service production from taking place, and this phenomenon in turn affects, in a negative way, the rate of national growth

14. weakens the growth of the construction industry by eroding mutual trust and respect,

15. Pours money unnecessarily to the project at hand at the expense of other new projects,

16. Distorts fair and equitable resource distribution,

17. Discourage investment, the investment on building construction by public clients wil be less, hence the number of projects will decrease in the future,

18. Creates skeptical outlook on appraisal of other new construction projects,

19. Some project owners (clients) become reluctant to affect additional payments to contractors and they view the cost overgrow as a fabricated thing. This will propel to delay the project and become a source of dispute among participants of the project,

20. Creates frustration on stakeholders.

One of the common effects of cost overgrow is delay; this in turn affects clients, consultants and contractors. Furthermore, lengthy delays increase cost overgrows tremendously. Excessive cost overgrow requires additional budget, this in turn eat up the scarce financial resources of the country, which lead to further budget short fall for construction projects. This prevents the planned increase in property and service production from taking place, and this phenomenon in turn affects, in a negative way, the rate of national growth. Cost overgrow will also be a source of dispute among stakeholders and it will lead to adversarial relationship among project participants. Project owners will lose confidence on consultant and on professionals in general. To the industry as a whole, cost overgrows could bring about a drop in building activities, bad reputation, and inability to secure project finance easily form public authorities in the future. Al these effects undermine the viability and sustainability of the construction industry.

\section{Conclusion}

Identification of causes of cost overgrow is a prerequisite to minimize or to avoid cost overgrow in the construction industry. The main objective of this research is, therefore, to identify and investigate the critical causes and effects of cost overgrow on public building construction projects in Ethiopia. Desk study was used to identify the existence and extent of cost overgrows on public building construction projects. The analysis of the results from the open-ended part of the questionnaire was carried out using descriptive analysis. From the results of the analysis of desk study and respondents' responses the following conclusions are drawn.

$\rightarrow$ Justification of the existence and extent of cost overgrow on public building construction projects is important before identifying the causes of cost overgrow, public building projects investigated in the research suffered cost overgrow in their execution. For these public building construction projects, the actual cost overgrows of the contract amount.

$\rightarrow$ Rate of cost overgrow is found to be influenced by the contract amount. The regression analysis of the data gathered from desk study for more public building construction projects shows that the rate of cost overgrow is found to decrease with increase in the contract amount.

$\rightarrow$ There are significant variations in the total amount of cost overgrow for the different types of public building construction projects investigated in this research. From the survey educational buildings have the lowest rate of cost overgrows, where as health buildings have the highest rate of cost overgrow.

$\rightarrow$ From the results of this thesis many causes of cost overgrow were identified by the respondents. The causes of cost overgrow were identified based on the responses of the respondents. The most frequent causes of cost overgrow are also identified by the research based on the ranking of the rate of occurrences of the variables of cost overgrow. The most common causes of cost overgrow are inflation or increase in the cost of construction materials, change in foreign exchange rate (for imported materials), change orders and/or lack of control on excessive change orders, failure to identify problems and institute the necessary and timely actions. 
$\rightarrow$ There is strong correlation on the responses of respondents, i.e. between client and contractor; between contractor and consultant; and between client and consultants in ranking causes of cost overgrow and the rates of occurrences of the variables of cost overgrow.

$\rightarrow$ From the research it was found that consultants are most of the time found to be responsible followed by clients for the problems of cost overgrow in the construction industry.

$\rightarrow$ From this research clients are those who are severely affected by cost overgrow, since they are forced to look for additional money to complete the construction project. However, it should be noted that clients, consultants, contractors, and even the national economy of the country are al affected by cost overgrow. 